\title{
Properties of SiC Resistive Memory for Harsh Environments
}

\author{
Katrina Morgan ${ }^{1}$, Junqing Fan², Ruomeng Huang ${ }^{1}$, Le Zhong ${ }^{2}$, Robert Gowers ${ }^{2}$, Liudi Jiang ${ }^{2}$ and Kees \\ De Groot ${ }^{1}$ \\ ${ }^{1}$ Nano Research Group. \\ Electronics and Computer Science \\ University of Southampton, Southampton, Hampshire, United Kingdom, SO171BJ \\ Phone: +442380593126 E-mail: kam2g11@soton.ac.uk \\ ${ }^{2}$ Faculty of Engineering and the Environment. \\ University of Southampton, Southampton, Hampshire, United Kingdom, SO171BJ
}

\begin{abstract}
Amorphous silicon carbide resistive memory cells are shown to exhibit the highest $\mathbf{R}_{\mathrm{OFF}} / \mathbf{R}_{\mathrm{ON}}$ ratio recorded for any resistive memory in pulsed switching. The switching characteristics are investigated and fitted to a numerical model. The SET mechanism for these cells is found to be due to ionic motion without joule heating contributions, leading to large $\mathrm{V}_{\text {SET }}$. The high thermal conductivity and resistivity of the SiC memory cells result in slow switching but, with high state and thermal stability, show potential for harsh environment use. Radiation properties of $\mathrm{SiC}$ memory cells are investigated. No change was seen in switching properties nor in conductive mechanism, up to $2 \mathrm{Mrad}(\mathrm{Si})$ using ${ }^{60} \mathrm{Co}$ ionizing gamma radiation.
\end{abstract}

\section{Introduction}

Resistive memory has the potential to become a successful non-volatile memory, replacing semiconductor memories with simple, low power, and high density arrays. Resistive memory can be switched between a high resistance state (HRS) and low resistance state (LRS) through an applied bias. Two types of resistive memory exist; valence change memory (VCM) and electrochemical memory (ECM) [1].

ECM cells work based upon the movement of cations within an electrolyte layer. Amorphous $\mathrm{SiC}$ shows great potential as the electrolyte layer with excellent state stability and ultra-high ratio memory cells, although slow to switch [2,3]. This was previously attributed to a high diffusion barrier of $\mathrm{SiC}$ for $\mathrm{Cu}$ along with high thermal conductivity [4]. However, no qualitative investigations into the switching characteristics were performed and no study was conducted into the SET mechanism.

Here, $\mathrm{Cu} / \mathrm{a}-\mathrm{SiC} / \mathrm{Au}$ memory cells are investigated through the analysis of pulsed measurements in comparison to a previously reported analytical model [5]. SiC's good thermal and state stability indicates a potential use for these memory cells in space and nuclear applications. Radiation tolerance of ECM cells are investigated through the ionizing irradiation of $\mathrm{Cu} / \mathrm{a}-\mathrm{SiC} / \mathrm{Au}$ memory cells up to a high dose of $2 \mathrm{Mrad}(\mathrm{Si})$.

\section{Switching Characteristics}

$\mathrm{Cu} / \mathrm{a}-\mathrm{SiC} / \mathrm{Au}$ memory cells were fabricated as described in previous publications [6]. Fig. 1 shows a graphical representation of the layout. An Agilent B1500A semiconductor parameter analyzer was used to perform DC and pulsed measurements. Pulsed measurements resulted in $\mathrm{R}_{\mathrm{OFF}} / \mathrm{R}_{\mathrm{ON}} \geq 10^{8}$ as shown in Fig. 2. This is the highest ratio recorded for pulse switching of any resistive memory, as a result of the large $\mathrm{R}_{\mathrm{OFF}}$ value, which is thought to originate from the presence of a $\mathrm{Cu} / \mathrm{SiC}$ Schottky Barrier [2].

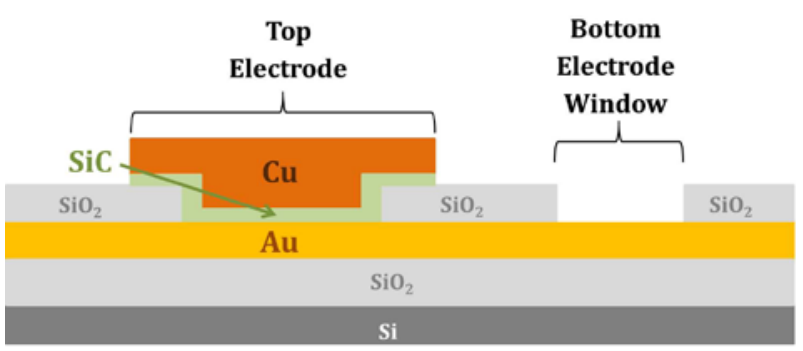

Fig. 1 Graphical representation of Cu/a-SiC/Au memory cells.

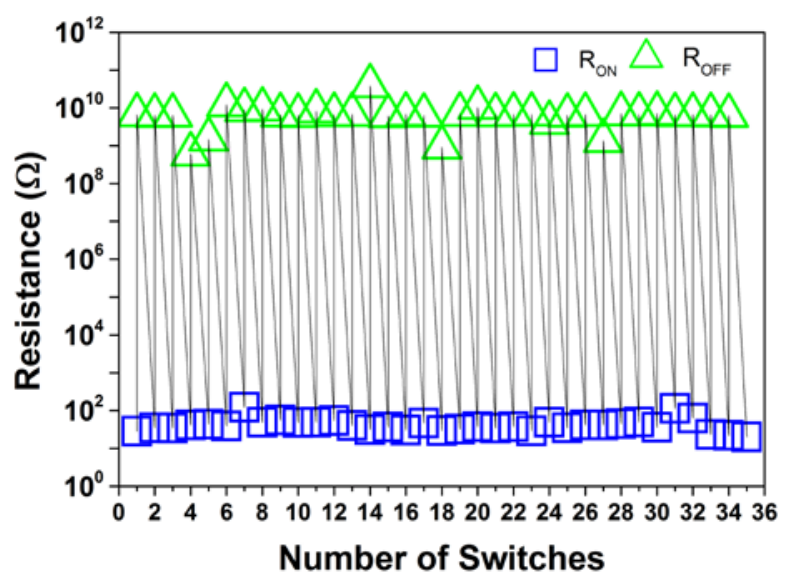

Fig. $2 \mathrm{Cu} / \mathrm{a}-\mathrm{SiC} / \mathrm{Au}$ memory cell measured using $-5 \mathrm{~V}$, 0.5s pulse for RESET and $+10 \mathrm{~V}, 0.01$ s pulse for SET, exhibiting $\mathrm{R}_{\mathrm{ON}} \sim 30 \Omega$, $\mathrm{R}_{\mathrm{OFF}} \sim 10^{10} \Omega$, resulting in $\mathrm{R}_{\mathrm{OFF}} / \mathrm{R}_{\mathrm{ON}} \geq 10^{8}$.

A numerical model of the switching mechanisms for ECM cells has been reported in Ref [5], modelled as filament growth and reduction based on ion migration through 
thermally assisted hopping as shown by eq. (1),

$$
\frac{d \phi}{d t}=A e^{-\frac{E_{A 0}-\alpha q V}{k T_{0}\left(1+\frac{V^{2}}{8 T_{0} \rho k_{t h}}\right)}}
$$

where $\phi$ is the filament diameter, $\mathrm{A}$ is a constant, $\mathrm{E}_{\mathrm{A} 0}$ is the energy barrier for ion hopping, $\alpha$ is the barrier lowering coefficient, $\mathrm{q}$ is the elementary charge, $\mathrm{V}$ is the applied voltage, $\mathrm{k}$ is the Boltzmann constant, $\mathrm{T}_{0}$ is room temperature, $\rho$ is the electrical resistivity and $k_{t h}$ is the thermal conductivity.

This work introduces a condition to this model, enabling the switching mechanism to be determined. If $\rho \mathrm{k}_{\mathrm{th}}>>\mathrm{V}^{2} / 8 \mathrm{~T}_{0}$, eq. (1) reduces to eq. (2) indicating the mechanism is due to ionic motion only without any joule heating contributions.

$$
\frac{d \phi}{d t}=A e^{-\frac{E_{A 0}-\alpha q V}{k T_{0}}}
$$

For the SET process in the $\mathrm{Cu} / \mathrm{a}-\mathrm{SiC} / \mathrm{Au}$ memory cells, high thermal conductivity $\left(\mathrm{k}_{\mathrm{th}}=490 \mathrm{~W} / \mathrm{mK}\right)$ along with extremely high $\mathrm{R}_{\mathrm{OFF}}$ values leads to an ultra-high $\rho \mathrm{k}_{\mathrm{th}}$ value compared to other memory cells in literature, resulting in purely ionic motion with no joule heating contribution. Pulsed measurements were conducted to investigate the switching mechanism and verify this condition.

The switching mechanism was experimentally identified using pulsed measurements with varied durations. Fig. 3 shows that for the SET mechanism, an exponential relation exists between $\mathrm{V}_{\mathrm{SET}}$ and $\mathrm{t}_{\mathrm{SET}}$. This is seen in eq. (2) hence showing agreement to the numerical model whereby the SET process in these SiC memory cells are determined by ionic motion without joule heating contributions. The large $\mathrm{V}_{\mathrm{SET}}$ required for these memory cells can be attributed to the lack of joule heating, originating from low resistivity and high thermal conductivity of SiC.

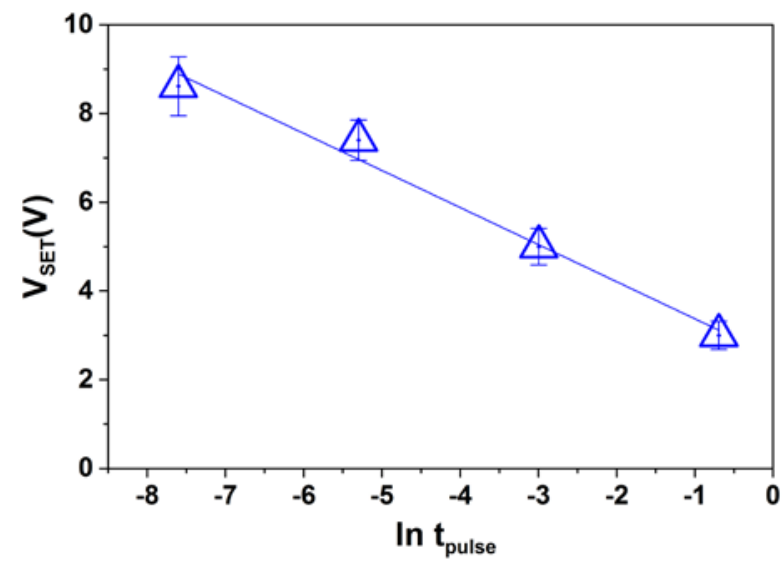

Fig. 3 Time dependencies of SET mechanism for pulsed switching of $\mathrm{Cu} / \mathrm{a}-\mathrm{SiC} / \mathrm{Au}$ memory cells, displaying an exponential relation.

\section{Radiation Effects}

$\mathrm{Cu} / \mathrm{a}-\mathrm{SiC} / \mathrm{Au}$ memory cells were irradiated using ${ }^{60} \mathrm{Co}$ ionizing radiation up to $2 \mathrm{Mrad}(\mathrm{Si})$. Fig. 4 shows two sets of pulsed measurements, before and after radiation. The ultra-high average $\mathrm{R}_{\mathrm{OFF}} / \mathrm{R}_{\mathrm{ON}} \geq 10^{8}$ remains after radiation. DC sweep measurements were conducted verifying LRS conduction mechanism remained as ohmic conduction, whilst the HRS state remained as Schottky emission.

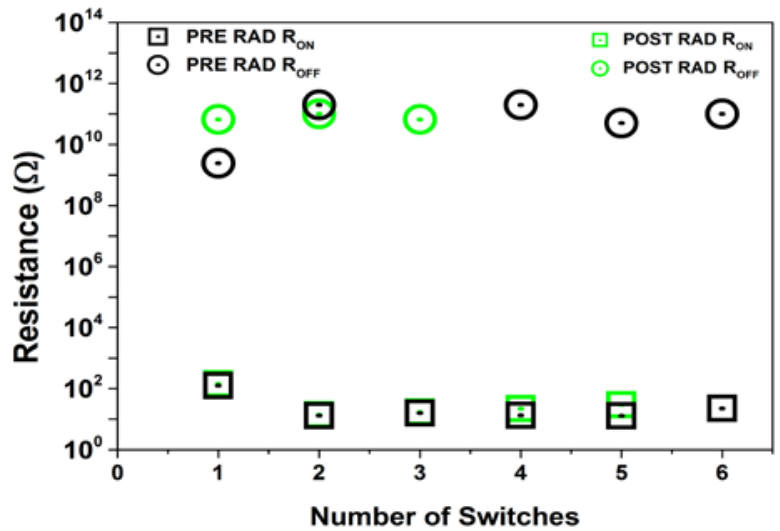

Fig. $4 \mathrm{Cu} / \mathrm{a}-\mathrm{SiC} / \mathrm{Au}$ memory cell measured before and after $2 \mathrm{Mrad}(\mathrm{Si})$, with a ratio of $\mathrm{R}_{\mathrm{OFF}} / \mathrm{R}_{\mathrm{ON}} \geq 10^{8}$ maintained.

No noticeable radiation induced change in conduction mechanisms, with little impact on $\mathrm{R}_{\mathrm{OFF}} / \mathrm{R}_{\mathrm{ON}}$ up to $2 \mathrm{Mrad}(\mathrm{Si})$ indicates the potential use for $\mathrm{SiC}$ resistive memory in space and nuclear industries.

\section{Conclusions}

$\mathrm{Cu} / \mathrm{a}-\mathrm{SiC} / \mathrm{Au}$ memory cells have shown pulsed switching with ultra-high $\mathrm{R}_{\mathrm{OFF}} / \mathrm{R}_{\mathrm{ON}} \geq 10^{8}$, the highest published ratio to date, originating from high $\mathrm{R}_{\mathrm{OFF}}$. The high $\mathrm{R}_{\mathrm{OFF}}$ and thermal conductivity of these memory cells indicates that, using condition $\rho k_{t h}>>V^{2} / 8 T_{0}$, the SET mechanism is due to ionic motion with no joule heating contributions resulting in slow switching memory cells. These memory cells are radiation hard up to $2 \mathrm{Mrad}(\mathrm{Si})$ with negligible change seen for ratio and conduction mechanisms, indicating their potential use in harsh environments.

\section{Acknowledgements}

This work was supported by an EPSRC Case scheme award, EP/J002968/1, and by AWE, UK.

\section{References}

[1] R. Waser and M. Aono, Nat Mater 6, (2007) 833.

[2] L. Zhong, P. Reed, R. Huang, C. de Groot and L. Jiang, Solid-State Electronics. 94 (2014) 98.

[3] L. Zhong, L, Jiang, R. Huang and C. H. de Groot, Applied Physics Letters 104 (2014) 093507.

[4] W. Lee, M. Siddik, S. Jung, J. Park, S. Kim, J. Shin, J. Lee, S. Park, M. Son and H. Hwand, Electron Device Letters, IEEE, 32 (2011) 1573.

[5] D. Ielmini, Electron Devices, IEEE Transactions on 58 (2011) 4309. 